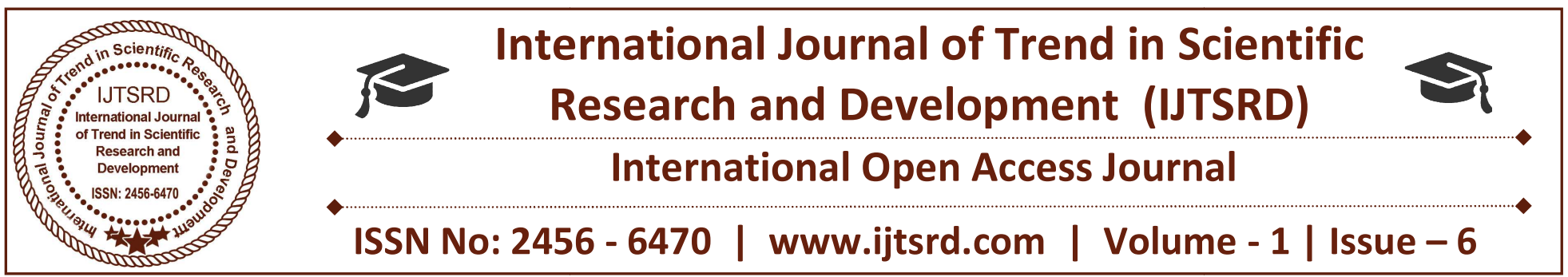

\title{
Synthesis of Epoxidizedcardanol from CNSL (Vietnam) by Glacial Acetic Acid and Hydrogen Peroxide
}

\author{
Bach Trong Phuc, Vu Van Hai, Nguyen Thi Hien, Nguyen Thanh Liem \\ Hanoi University of Science and Technology, Ha Noi, Viet Nam
}

\begin{abstract}
Cardanol obtained by vacuum distillation of cashew nut shell liquid (CNSL) at $220-230{ }^{\circ}$ Cand $2-4$ mmHg.Epoxidizedcardanol (ECD), derived from cardanol was synthesized at $65^{\circ} \mathrm{C}, 2 \%$ catalyst, $\mathrm{DB} / \mathrm{AA} / \mathrm{H}_{2} \mathrm{O}_{2}: 1 / 0.5 / 1$, stirring rates are $1800 \mathrm{r} / \mathrm{mand}$ characterized by FT - IR, ${ }^{1} \mathrm{H}-\mathrm{NMR},{ }^{13} \mathrm{C}-\mathrm{NMR}$, TGA.
\end{abstract}

Keywords: Cashew nut shell liquid, cardanol, epoxidizedcardanol

\section{Introduction}

In industrial applications the use of natural products is increasing due to concerns over environmental issues, waste disposal and depletion of non-renewable resources. Owing to the growing pressure to reduce carbon dioxide emissions by fossil fuels, the need for developing alternate chemical feed stocks from renewable resources is immense. Furthermore, these materials are sometimes cheaper than petrochemicals.

Vietnam is the largest exporter of cashew nuts in the world. However, the cashew nut shell burns only while cashew nut shell oil has great economic potential. Cashew nut shell liquid (CNSL) constitutes nearly one-third of the total nut weight; thus, a large amount of CNSL is formed as a by-product of the mechanical processes used to render the cashew kernel edible and its total production approaches one million tons annually. Thermally treated CNSL, whose main component is cardanol, aphenolderivative mainly having a meta substituent of a C15 hydrocarbon chain with one to

Three double bonds, has various potential industrial utilizations, such as resins, friction lining materials, and surface coatings; however, only a small part of the CNSL that is produced is used in the industrialfield. ${ }^{3}$

Cardanol a by product of CNSL has been used to produce phenalkamine low temperature curing agents for the durable epoxy coatings for marine applications $^{3}$. Frictional materials are made by polymerizing side chain of cardanol, followed by cross polymerization with formaldehyde to yield cardanol formaldehyde resin. Cardanol based polyols have been developed for rigid polyurethane applications. Despite all these uses, only a fraction of the cardanol obtained from cashew nut processing is used in the industrial field. Therefore, there is an overwhelming interest to create new polymer materials with improved performance from cardanol for new applications.

\section{Experimental}

\subsection{Materials}

CNSL was purchased from Cat Loi Cashew Oil Production \& Export JSC (Vietnam). Cardanol was purified by double-vacuum distillation at $230-240^{\circ} \mathrm{C}$ under 2-5 mmHg. ${ }^{2,5}$ Glacial acetic acid (99- 100\%) was obtained from Merck, fomic acid and Hydrogen peroxide $(30 \% \mathrm{~V} / \mathrm{V})$ from China. $p$-toluenesulfonic acid from Merck. Solvent ether and toluene (sulfur free) was obtained from China. 


\subsection{Synthesis of epoxidizedcardanol (ECD)}

Epoxidizedcardanol was synthesized by reaction of cardanol with glacial acetic acid anh hydrogen peroxide using p-toluenesulfonic acid as a catalyst, toulen as a solvent. According to a literature procedure adopted for epoxidation of vinyl double bonds. $^{8}$

In a four neck a round bottom flask equipped with a mechanical stirrer, thermometer sensor, and reflux condenser, Cardanol, glacial acetic acid, $p$ toluenesulfonic, and toluene were charged. The mixture was heated to temperature determined and $30 \% \mathrm{H}_{2} \mathrm{O}_{2}$ was added slowly and allowed. After the reaction was complete, the crude product was filtered and washed with a saturated solution of $\mathrm{Na}_{2} \mathrm{CO}_{3}$ and distilled water, and then dried with anhydrous sodium sulfate. Finally, toluene was removed by distillation under vacuum at $80{ }^{\circ} \mathrm{C}$ for $2 \mathrm{~h}$ to yield the product. ${ }^{13,14,15}$

\section{Results and Discussion}

\subsection{The effect of temperature cardanolepoxidation}

Cardanol epoxy reactions with reactive temperature from $55 \div 70^{\circ}$ C. After washing and drying, the samples were analyzed for content of epoxy group and iodine index to calculate the efficiency of the reaction. The analysis results are shown in Figure 1.

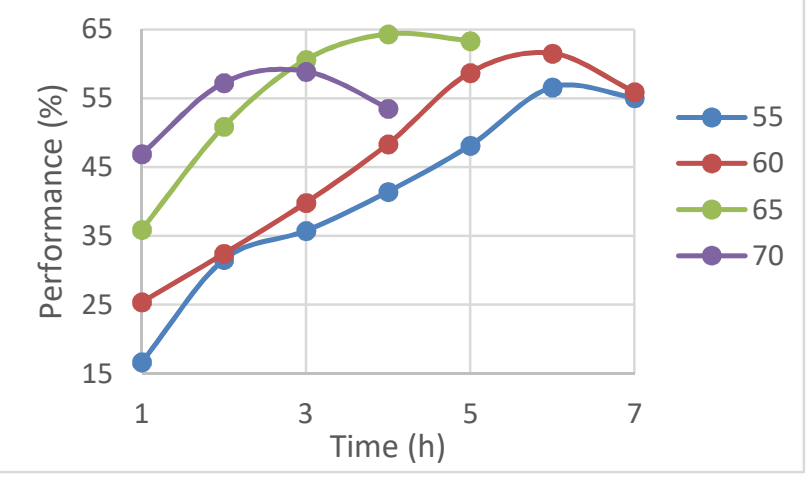

Fig. 1: Effect of temperature on cardanolepoxidation

The results in Figure 3.4 show that the performance of the reaction is lowest at $55^{\circ} \mathrm{C}$, highest at $65^{\circ} \mathrm{C}$. When raising the temperature, the efficiency of the reaction increases. However, when the temperature rises too high, the reaction efficiency decreases sharply. Because high temperatures, the formed epoxy group is easily broken by temperature. A temperature of $65^{\circ} \mathrm{C}$ is the optimum temperature for cardanol epoxide response to the survey conditions. We choose a temperature of $65^{\circ} \mathrm{C}$ to conduct a survey of the next parameters of the reaction.

\subsection{The Effect of catalyst on epoxidation reaction}

Examine the effect of catalyst on cardanolepoxidation reaction: $1,2,3,4 \%$ over oil at $65^{\circ} \mathrm{C}$. The analysis results are shown in Figure 2.

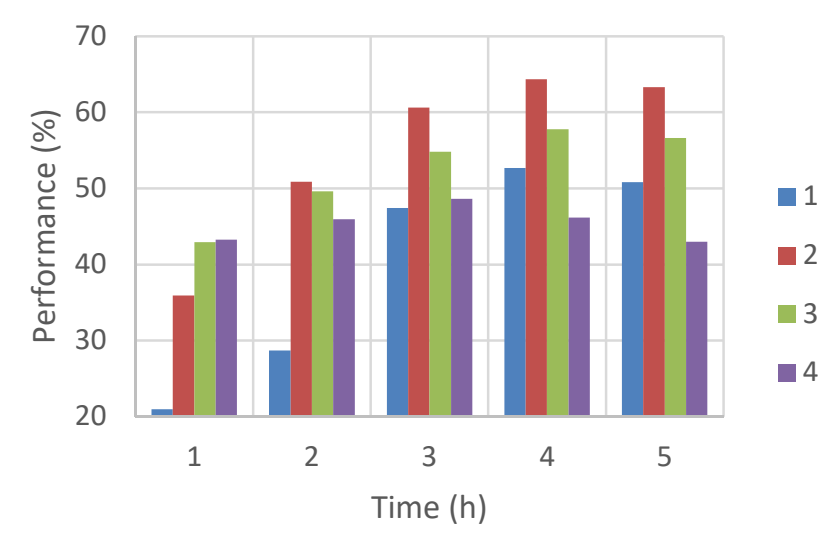

Fig 2: Effect of catalyst on epoxidation reaction

The results in Figure 2 show that the performance of the reaction is lowest with catalyst was $4 \%$, the highest with catalyst was $2 \%$. When the catalyst increases the performance of the reaction increases. However, when the catalyst is too high, the reaction efficiency decreases. Because p-toluene suforic is a potent, acidic catalyst, causing the epoxy ring opening reaction. $2 \%$ catalyst is the optimal catalyst for cardanolepoxidation with the survey conditions. We chose a $2 \%$ catalyst to conduct the next parameter of the reaction

\subsection{The Effect of ingredients in the mixture on epoxidation reaction}

The ratio of substances is DB / AA / $\mathrm{H}_{2} \mathrm{O}_{2}$ is $1 / 0.5 / \mathrm{x}$ with $\mathrm{x}$ is $0.5,1,1.5,2$ at $65^{\circ} \mathrm{C}$, catalyzing $2 \%$ of cardanol volume. The results of the experiment are shown in Figure 3

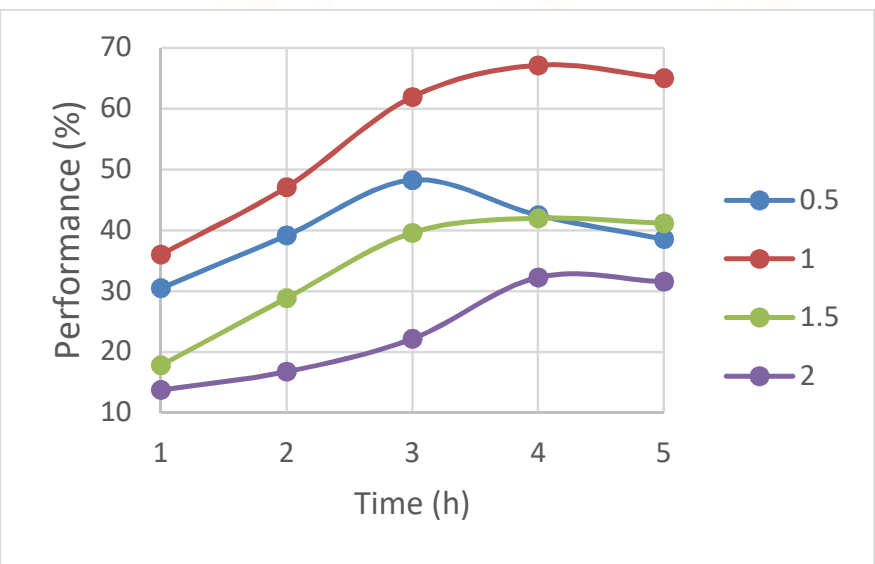

Fig 3: Effect of ingredients in the mixture on epoxidation reaction 
The results in Figure 3 show that the performance of the reaction is lowest when the ratio of $\mathrm{DB} / \mathrm{H}_{2} \mathrm{O}_{2}$ is $1 / 2$ and $1 / 1$ is the highest. When $\mathrm{H}_{2} \mathrm{O}_{2}$ increases the performance of the reaction increases. However, when $\mathrm{H}_{2} \mathrm{O}_{2}$ increases too high, the reaction efficiency decreases. Because the reaction has reached saturated levels of $\mathrm{H}_{2} \mathrm{O}_{2}$ or an increase in the amount of $\mathrm{H}_{2} \mathrm{O}_{2}$ that still increases the formation of the epoxy group while increasing both the epoxy ring-opening reaction.

The ratio of $\mathrm{DB} / \mathrm{AA} / \mathrm{H}_{2} \mathrm{O}_{2}$ to $1 / 0.5 / 1$ is the optimum ratio for cardanol epoxide response to the survey conditions.

\subsection{The Effect of stirring speed on epoxidation reaction}

Stirring rates are $1200,1500,1800,2100 \mathrm{r} / \mathrm{m}$ at $65^{\circ} \mathrm{C}$, catalytic $2 \%$ by volume of cardanol and the ratio of $\mathrm{DB} / \mathrm{AA} / \mathrm{H}_{2} \mathrm{O}_{2}$ is $1 / 0.5 / 1$. The results of the experiment are shown in Figure 4

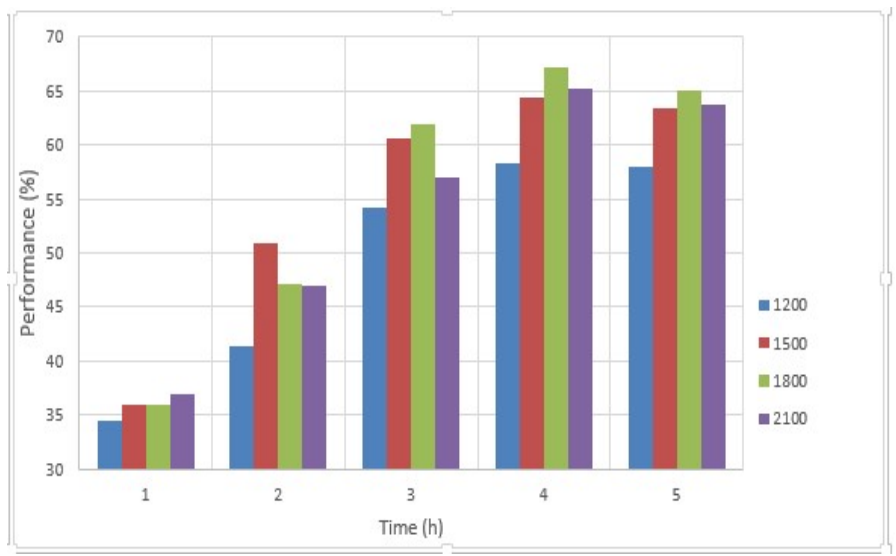

Fig.4: Effect of stirring speed on epoxidation reaction

The performance of the reaction is lowest when the stirring speed $1200 \mathrm{r} / \mathrm{m}$, is highest when the stirring speed is $1800 \mathrm{r} / \mathrm{m}$. When stirring speed increases the performance of the reaction increases. However, when the stirring speed is too high, the reaction efficiency decreases. Because the reaction system is heterologous to cardanol, toluene is hydrophobic, acetic acid and $\mathrm{H}_{2} \mathrm{O}_{2}$ are hydrophilic, so dispersion of substances in the reaction system is very necessary. The reaction will take place on the surface of the phase separation. Under varying stirring speed, the exposure and phase-difference times result in different reaction results. We chose a stirrer speed of $1800 \mathrm{r} / \mathrm{m}$ to conduct a survey of the next parameters of the reaction.

\subsection{FTIR spectralanalysis}

FT-IR technique was employed first to study the structures of cardanol and ECD. The FI-IR spectra of cardanol and ECD are depicted in Figure 5. In the spectrum of cardanol, there are several typical peaks: the phenolic hydroxyl group (3333 and $1348 \mathrm{~cm}_{-1}$ ), C$\mathrm{H}$ stretching of the inner unsaturated moiety (3009 $\mathrm{cm}_{-1}$ ), methyl, methylene and methine groups (2924, 2853 and $\left.1454 \mathrm{~cm}_{-1}\right), \mathrm{C}=\mathrm{C}$ on aromatic ring (1589 $\mathrm{cm}_{-1}$ ), symmetric and asymmetric stretching of $\mathrm{C}=\mathrm{C}$ (1263 $\mathrm{cm}_{-1}, 1153 \mathrm{~cm}_{-1}$ ), vibration of the four hydrogen atoms adjacent to the benzene ring (779 $\left.\mathrm{cm}_{-1}, 692 \mathrm{~cm}_{-1}\right)$.

In the spectrum of ECD, there are alsosome characteristic peaks: the phenolic hydroxyl group (3373 and $1373 \mathrm{~cm}_{-1}$ ), methyl and methylene (2926 and $\left.2854 \mathrm{~cm}_{-1}\right)$, epoxy group $\left(848-918 \mathrm{~cm}_{-1}\right)$. And two obvious changes are observed in the spectrum of ECD. First, the peak of C-H in the innerunsaturated moiety at $3009 \mathrm{~cm}_{-1}$ is absent because of the conversion to epoxide. Second, the characteristic features of the epoxy group are found at 848, $918 \mathrm{~cm}_{-1}$. Furthermore, the typical peak of phenolic hydroxyl group still exists. These indicate that cardanol had been converted into ECD.

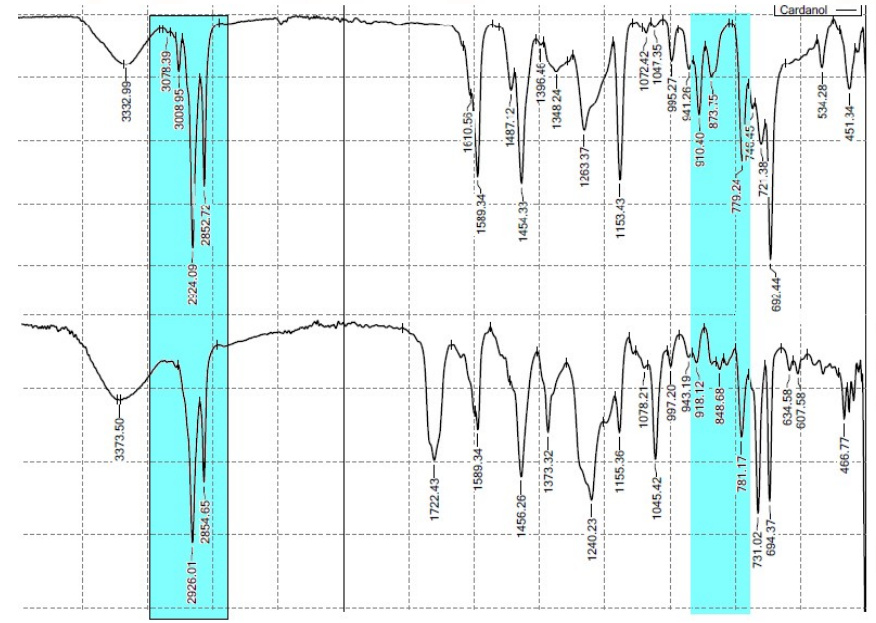

Fig 5: FTIR spectral of cardanol and ECD

\section{3. ${ }^{1} \mathrm{H}-\mathrm{NMR}$ and ${ }^{13} \mathrm{C}-\mathrm{NMR}$ spectraanalysis}

Figure 6 display the ${ }^{1} \mathrm{H}$ - NMR spectra of cardanol and ECD, respectively. The characteristic peaks at 6.6-7.3 ppm correspond to the protonson the benzene ring. Compared to the spectra of cardanol and ECD, the peaks at $5.4 \mathrm{ppm}$, corresponding to the proton of $\mathrm{CH}=\mathrm{CH}$ - in cardanol, have almost disappeared in ECD. This indicates that the unsaturated double bonds on the alkyl chain have been converted into epoxy groups during the epoxidation. The phenolic hydroxyl group at $5.2 \mathrm{ppm}$ is still observed. Additionally, the 
new peaks at $2.9-3.2 \mathrm{ppm}$ indicate epoxy groups in ECD. Furthermore, the changed chemical shift of the peaks at $1.3-1.8 \mathrm{ppm}$ also supports the formation of epoxidized groups.

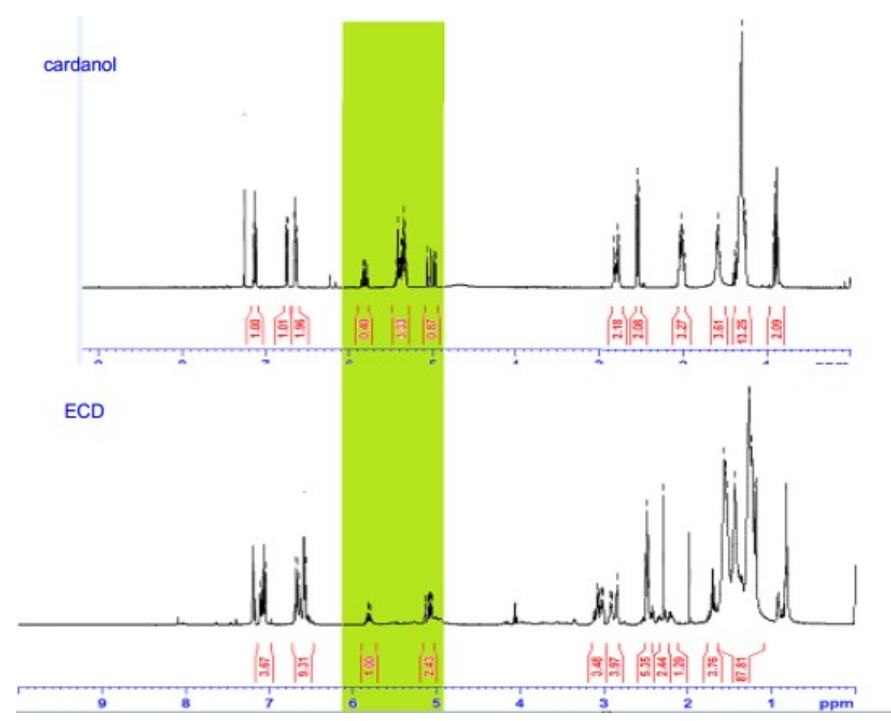

Fig.6. ${ }^{1} \mathrm{H}$ - NMR spectra of cardanol and ECD

Figure 7 display the ${ }^{13} \mathrm{C}-\mathrm{NMR}$ spectra of cardanol and ECD.The ${ }^{13} \mathrm{C}-\mathrm{NMR}$ peaks at $114.7-137.1 \mathrm{ppm}$ are present in Figure 7 assigned to carbons 11, 13 and 14 have dissappeared. The epoxy groups distinguish between cardanol and ECD with the new cacbons in the epoxy.

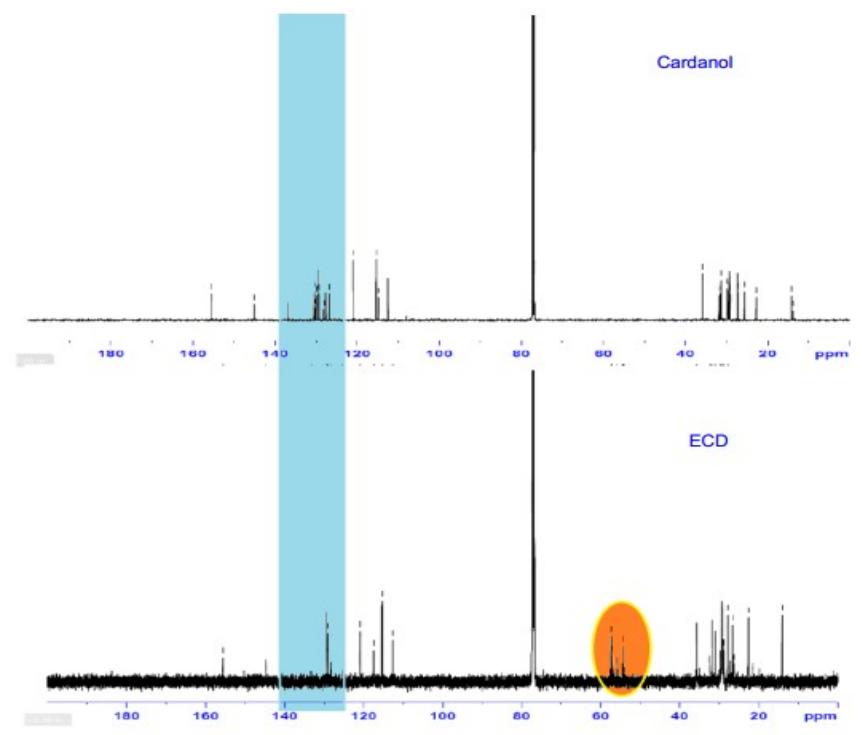

Fig.7. ${ }^{13} \mathrm{C}$ - NMR spectra of cardanol and ECD.

\subsection{Thermal stability of ECD}

Figure 8 shows the TGA curves of cardanol and ECD heated in nitrogen at the rate of $10^{\circ} \mathrm{C} / \mathrm{min}$. It can be obserced that $10 \%$ weight loss $\left(\mathrm{T}_{10}\right)$ and $50 \%$ weight loss $\left(\mathrm{T}_{50}\right)$ of cardanol happened at 285 and $409^{\circ} \mathrm{C}$ and the temperature is 200 and $393^{\circ} \mathrm{C}$ for the ECD

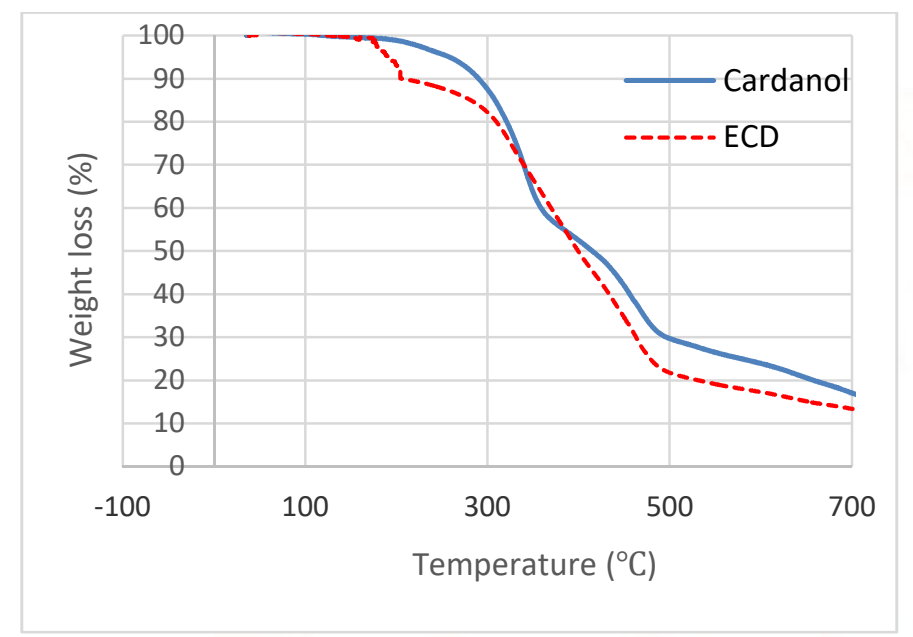

Fig.8. TGA curves of cardanol and ECD samples

The decomposition rate of ECD is faster than that of cardanol. So, the thermal stability of ECD is lower than that of cardanol. These results indicate the ECD is suitable for application at medium temperature.

Experimental results showed that $60^{\circ} \mathrm{C}$ was the most suitable temperature for cardanol epoxide oxidation with $91 \%$.

\section{Conclusion}

In the study, Cardanol - derived ECD was synthesized at $65^{\circ} \mathrm{C}, 2 \%$ catalyst, DB/AA/ $\mathrm{H}_{2} \mathrm{O}_{2}$ : $1 / 0.5 / 1$, stirring rates are $1800 \mathrm{r} / \mathrm{m}$ and characterizedby FT - IR, ${ }^{1} \mathrm{H}-\mathrm{NMR},{ }^{13} \mathrm{C}-\mathrm{NMR}$.

However, the effect of the reaction is not high (70\%) due to the high temperature, which is more likely to occur when the epoxy ring is opened.

\section{REFERENCES}

[1] VõPhiêncùngcộngsự

$(1981)^{\text {“6 }}$

Polymetrêncơsởcardanol”, TạpchíHóahọc, T.19, số 2, tr. 3-9.

\section{[2]}

VõPhiêncùngcộngsự. “Polymetrêncơsởcardanol”. Tạpc híHóahọc, T.31, số 1, tr. 1-4,1993.

[3] P.H.Gedam,P.S.Sampathkumaran. "Cashew nut shell liquid: extraction, chemistry and applications. Progress in organic coatings, 14(1986), P.115 - 157.

[4] Izzo P, Dawson C (1949) Cashew nut shell liquid. VI: the olefinic nature of anacardic acid. J Org Chem 14:1039-1047.

[5]Paramashivappa R, Kumar P, Vithayathil P, Rao A (2001) Novel method isolation of major phenolic 
constituents from

cashew

(AnacardiumOccidentale L.) nut shell liquid. J Agric Food Chem 49:2548-2551.

[5] Oghome P, Kehinde A (2004) Separation of cashew nut shell liquid by column chromatography. Afr J SciTechnol 5:2-95.

[6] "Synthesis and curing behaviors of a crosslinkable polymer from cashew nut shell liquid", Polymer, Volume 43, Issue 12, pp.3475-3481.

[7] Risfaheri, TunTedjaIrawadi , M. Anwar Nur: “ Isolation of cardanol from cashew nut shell liquid using the caccuumdistiliation method". Indonesian Journal of Agriculture 2(1), 11-20-2009.

[8] Zengshe Liu, Jie Chen, Gerhard Knothe, XiaoanNie, and Jianchun Jiang,Synthesis of epoxidizedcardanol and its antioxidative properties for vegetable oils and biodiesel , 11 Jan 2016

[9] Yadav R, Srivastava D. Blends of cardanol-based epoxidizednovolac resin and CTBN for application in surface coating: a study on thermal, mechanical, chemical and morphological characteristics. J Coat Technol Res, 2010;7:557-68.

[10] Yadav R, Srivastava D. Blends of cardanol-based epoxidizednovolac resin and CTBN for application in surface coating: a study on thermal, mechanical, chemical and morphological characteristics. J Coat Technol Res, 2010, 7:557-68.

[11] Wuzella G, Mahendran AR, Muller U, Kandelbauer A, Teischinger A. Photocrosslinking of an acrylatedepoxidized linseed oil: kinetics and its application for optimized wood coatings. J Polym Environ, 2012, 20:1063-74.

[12] ROSY ANTONY and C. K. S. PILLAI , Synthesis and Thermal Characterization of Chemically Modified Cardanol Polymers, Regional Research Laboratory, Trivandrum 695 019, India, 20 - September 1993, Pages 2129-2135.

[13] G.D. Yadavand D.V. Satoskar,'Kinetics of Epoxidation of Alkyl Esters of Undecylenic Acid Comparison of Traditional Routes vs. Ishii-Venturello Chemistry" , University of Bombay, Matunga, Bombay - 400 019, India, pp 397 - 407.

[14] AnneliseE. Gerbase, José R. Gregório, MárciaMartinelli, Márcia C. Brasil, and Ana N.F. Mendes Instituto de Química, , Epoxidation of Soybean Oil by the Methyltrioxorhenium $\mathrm{CH}_{2} \mathrm{Cl}_{2} / \mathrm{H}_{2} \mathrm{O}_{2}$ Catalytic Biphasic System, Universidade Federal do Rio
Grande do Sul, 91501-970, Porto Alegre, Brazil, February 2002, Paper no. J10060 in JAOCS 79, 179181.

[15] TaydeSaurabh- Patnaik M, Epoxidation of vegetable oils - International Journal of Advanced Engineering Technology, V.2, 2011, P.491-501.

[16] Paquot, C, Standard Methods for the Analysis of Oils, Fats and Derivatives, $6^{\text {th }}$ edn, Pergamon Press, Oxford, pp.66-70, 1979.

[17] Sacchi R, Addeo F, Paolillo L ${ }^{1} \mathrm{H}$ and ${ }^{13} \mathrm{C}$ NMR of virgin oil. An overview.MagnResonChem, 1997, 35:5133-5145.

[18] Vlahov G Application of NMR to the study of olive oils. ProgrNuclMagnResonSpectrosc, 1999, 35:341-357.

[19] Lyerla JR, Levy, GC Carbon-13 nuclear spin relaxation. In: Levy GC (ed) Topics in carbon-13 NMR spectroscopy. Wiley, New York, Chapter 3, 1974,pp 100-101.

[20] Freeman R, Hill HDW, Kaptein R Protondecoupled NMR. Spectra of carbon-13 with the nuclear Overhauser effect suppressed. J MagnReson, 1976, 7:327-329. 